\title{
What is a $\mathrm{Ca}^{2+}$ wave? Is it like an Electrical Wave?
}

\author{
Penelope A Boyden, ${ }^{1}$ Wen Dun ${ }^{1}$ and Bruno D Stuyvers ${ }^{2}$ \\ 1. Department of Pharmacology, Columbia University, New York; 2. Faculty of Medicine, Division of Biomedical Sciences, \\ Memorial University of Newfoundland, St. John's, NL, Canada
}

\begin{abstract}
Arrhythmia subcellular mechanisms are constantly being explored. Recent knowledge has shown that travelling Ca2+ waves in cardiac cells are critical for delayed afterdepolarisations and in some cases, early afterdepolarisations. In this review, we comment on the properties of cardiac $\mathrm{Ca}^{2+}$ waves and abnormal $\mathrm{Ca}^{2+}$ releases in terms of properties used to describe electrical waves; propagation, excitability and refractoriness.
\end{abstract}

\section{Keywords}

Delayed afterdepolarisation, early afterdepolarisation, Ca2+ waves, arrhythmias

Disclosure: The authors have no conflicts of interest to declare.

Received: 12 January 2015 Accepted: 25 February 2015 Citation: Arrhythmia \& Electrophysiology Review 2015;4(1):35-9 Access at: www.AERjournal.com Correspondence: Dr Penelope Boyden, Columbia University, 630 W 168th St NY NY 10032 US. E: Pab4@cumc.columbia.edu

Abnormalities in electrical rhythm were studied by Einthoven at the start of the 20th century. In the 1940s, studies by Bozler et al.' described contractile signals that appeared to be 'triggered' heart beats. Today we use the term delayed afterdepolarisations (DADS) to refer to oscillations in voltage that follow a driven action potential.

In the mid-1970s, progress was made when Lederer and Tsien developed a method to study the underlying electrical mechanism of $\mathrm{DADS}^{2}$ (see Figure 1). In a voltage clamped, multicellular canine Purkinje fibre, the transient depolarisation of the resting potential of the fibre was found to be due to a transient inward current $\left(I_{\mathrm{t} i}\right)$ (see Figure 1A). Many initially challenged this idea but these authors went on to show that $I_{\mathrm{ti}}$ was not an artifact and that the $I_{\mathrm{ti}}$ they recorded in Purkinje fibres was $\mathrm{Ca}^{2+}$ dependent (see Figure 1B).2,3 This was a relatively new concept for cardiac electrophysiology; that is, the idea that $\mathrm{Ca}^{2+}$ inside the cell could feed back and affect the electrics of the cell's membrane. In a recent review this was referred to as reverse mode excitation-contraction (EC) coupling. ${ }^{4}$

Here we will discuss the $\mathrm{Ca}^{2+}$ wave and address the question: 'Is it like the electrical wave with which we are all familiar?'

\section{Functional Anatomy}

A propagating electrical wave utilises the energy of the chemical gradients set up by the cardiac sarcolemma. ${ }^{5}$ Electrical waves rely on activation of a series of ion channels (eg. Na channel proteins) for forward propagation of the wave.

Propagation of a $\mathrm{Ca}^{2}+$ wave also depends on the energy stored in the myocyte. But in this case the energy comes from the presence of $\mathrm{Ca}^{2+}$ stored in the sarcoplasmic reticulum (SR). The SR is a specialised intracellular membrane structure that in a myocyte stores $\mathrm{Ca}^{2+}$ that has been pumped into it by a SR membrane pump, SERCA2. In the absence of $\mathrm{Ca}^{2+}$ influx through the plasma membrane or mischievous $\mathrm{Ca}^{2+}$ wandering the cytosol, the $\mathrm{Ca}^{2+}$ in SR stays in the SR. This is because the SR ligand-operated $\mathrm{Ca}^{2+}$ channel, the ryanodine receptor channel (RyR), which guards this SR Ca2+ store, has a low probability of opening.

Interestingly, just as surface membrane ion channels (eg. Na channels) are positioned in a specific array to provide for smooth electrical wave propagation, RyR channel proteins in myocytes, Purkinje and atrial cells are clustered and aligned in a specific micro-anatomic pattern (see Figure 2). ${ }^{7.8,19}$ Presumably, and particularly in the tubulated structures of ventricular myocytes, this specific patterning is to allow for uniform $\mathrm{Ca}^{2+}$ release from SR during the action potential (forward mode EC coupling). The orderly pattern of RyRs on the SR sets up a series of potential release sites of $\mathrm{Ca}^{2+}$ in the cell.

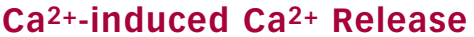

Fabiato's work on the properties of the cardiac SR provided a potential explanation for spontaneous $\mathrm{Ca}^{2+}$ release in mechanically skinned cells in which the SR and RyR were intact and excessive $\mathrm{Ca}^{2+}$ loading of the SR caused spontaneous $\mathrm{Ca}^{2+}$ release. ${ }^{9,10,11}$ The mechanism for increased probability of opening of RyR when the SR is heavily loaded with $\mathrm{Ca}^{2+}$ is still uncertain, but suggests that the RyR channel is sensitive to both cytosolic and luminal $\left[\mathrm{Ca}^{2+}\right]$ of the SR. Hence, the oscillatory character of a triggered arrhythmia in myocardium with a high cellular $\mathrm{Ca}^{2+}$ load may be due to further increase of $\mathrm{Ca}^{2+}$ entry into the cells during driven action potentials, which causes even more $\mathrm{Ca}^{2+}$ loading of the SR. So as soon as the release process has recovered after the electrically evoked $\mathrm{Ca}^{2}+$ release, the overloaded SR again releases a fraction of its $\mathrm{Ca}^{2+}$ into the cytosol. The requirement that the $\mathrm{Ca}^{2}+$ release mechanism must recover first (refractoriness) would explain the presence of a delay between aftercontractions and afterdepolarisations and the preceding beat. 

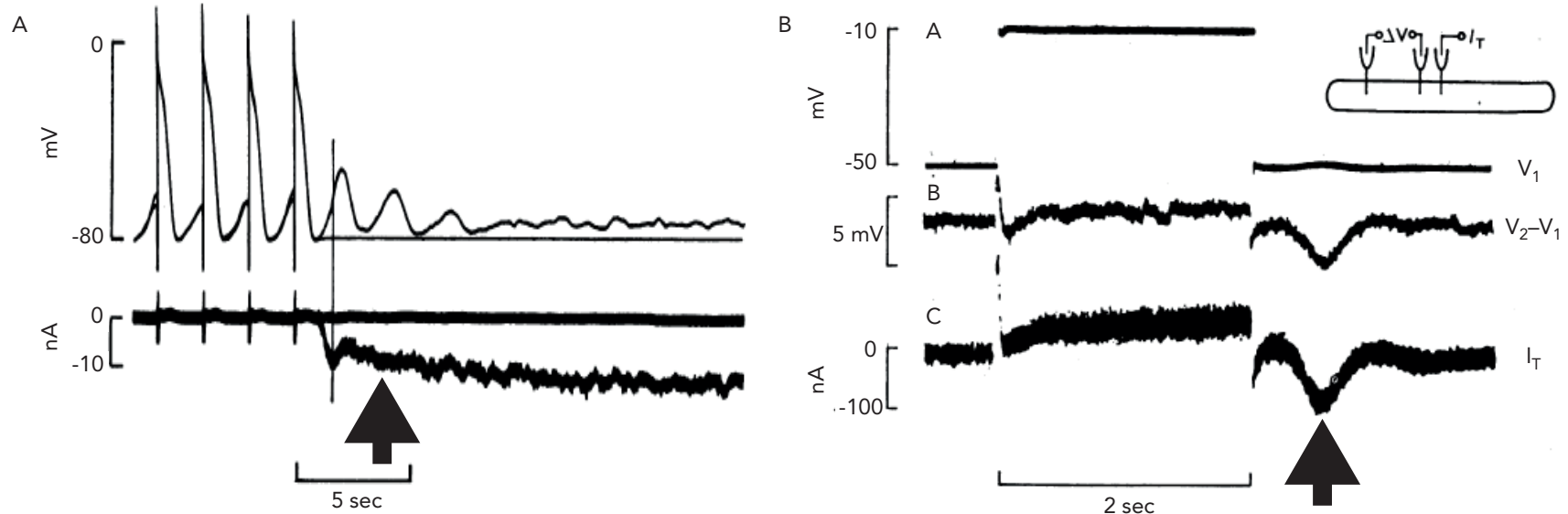

Panel A: The first manifestation of Ca2+ waves in cardiac cells, as observed by Lederer and Tsien $1976,{ }^{2}$ was the appearance of Iti currents (arrows) in voltage-clamped multicellular Purkinje fibres. Note phase 4 activity in this Purkinje strand when clamp was off. Panel B: Multiple experiments including the one shown here illustrated the Ca ${ }_{0}$ dependence of Iti $\left(K_{a s s}\right.$ et al., 1978). ${ }^{3}$

Figure 2: Architecture of $\mathrm{Ca}^{2+}$ Release Channels in Purkinje (A) and Atrial (B) Cells
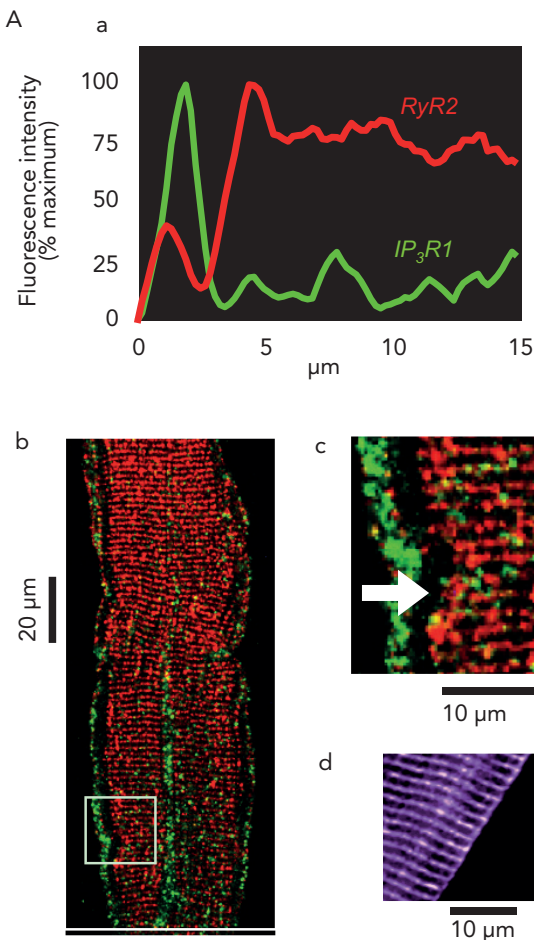

B
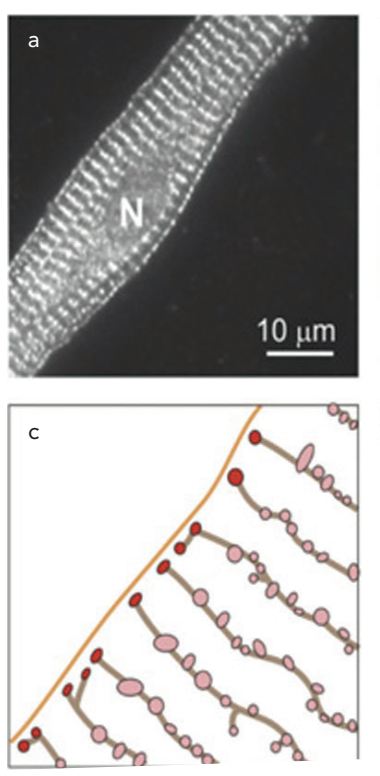

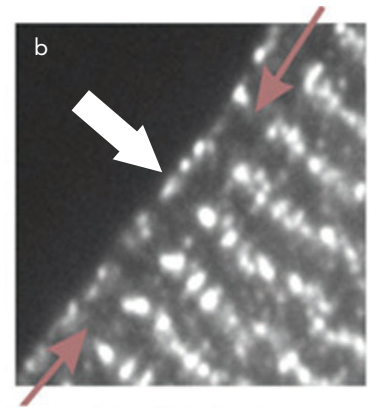

Gap in RyR distribution

- Sarcolemma

_ Sarcoplasmic reticulum

- Junction RyRs

- Non-junctional RyRs

The $\mathrm{Ca}^{2+}$ release channels (RyR) are organised into clusters (red dots in A $b$ and A.c). the clusters distribution follows a transverse striated pattern that matches the striation of the contractile filaments (not shown here). In Purkinje cells, junctional RyRs co-localise with IP3 receptor channels under the membrane. Note that both cell types show a gap in the RyR2 distribution. The gap is absent when isoform non-specific RyR antibody is used (A.d), indicating the presence of a different RyR isoform in the 'gap' of Purkinje cells. The same RyR2 organisation is found in atrial cells (B.a, B.b) wherein the same gap is interpreted here as a space filled by sarcoplamic reticulum with no channel and separating 'junctional' and 'Non-junctional' RyRs (B.C). In both cell types, this microanatomy shown schematically in B.c sets the stage for successful $\mathrm{Ca}^{2+}$ wave propagation. Adapted from Boyden et al., ${ }^{7}$ Thul et al. ${ }^{8}$ and Stuyvers et al. ${ }^{19}$

$\mathrm{Ca}^{2+}$ waves occurring in cardiac cells depend on the regenerative production of a diffusible molecule that triggers $\mathrm{Ca}^{2}+$ release from adjacent SR stores. Cytosolic $\mathrm{Ca}^{2+}$ is one such ion and thus the process is called $\mathrm{Ca}^{2+}$ induced (intracellular) $\mathrm{Ca}^{2+}$ release (CICR) (see Figure 3B). ${ }^{12}$ This schematic shows $\mathrm{Ca}^{2+}$ wave propagation from one RyR cluster to another. Calsequestrin (CASQ), a Ca2+ binding protein, is found in the SR lumen and aids wave propagation inside cells (see Figure $3 C$ ). The released $\mathrm{Ca}^{2+}$ constitutes a leak from the SR and tends to reduce the overload. This phenomenon has been observed in different forms, all of which fall under the general definition of $\mathrm{Ca}^{2+}$ leak: increased probability of opening of RyR in lipid bilayer experiments, ${ }^{13}$ a biochemically detectable loss of $\mathrm{Ca}^{2+}$ from the $\mathrm{SR}^{14}$
$\mathrm{Ca}^{2+}$ sparks in isolated cells and muscle; ;15,16 micro $\mathrm{Ca}^{2+}$ waves in isolated cells and muscle ${ }^{13,14}$ and Purkinje cells after infarction; 7,19 and multicellular cellular $\mathrm{Ca}^{2+}$ waves. ${ }^{17-19}$ The threshold for $\mathrm{Ca}^{2+}$ leak is reduced in some arrhythmogenic mutations of the $\mathrm{RyR}^{1{ }^{13}} \mathrm{CASQ}^{20}$ and in acquired dysfunction of the RyR such as in congestive heart failure and post Ml. ${ }^{721-23}$

Intracellular $\mathrm{Ca}^{2+}$ waves can be seen in normal canine atrial and Purkinje myocytes during forward mode EC coupling (see Figure 4). ${ }^{\text {? }}$ Here, a line of $\mathrm{Ca}^{2+}$ release is seen peripherally just after the plateau of the $\mathrm{AP}$ and this $\mathrm{Ca}^{2+}$ then via $\mathrm{CICR}$, sets up a $\mathrm{Ca}^{2+}$ transient that moves to the core of the Purkinje cell (see Figure 4). 
Figure 3: Simple Schematic Showing the Important Components of $\mathrm{Ca}^{2+}$ Wave Propagation

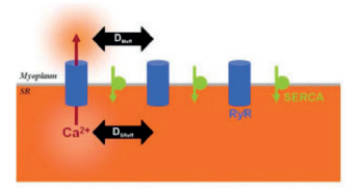

B

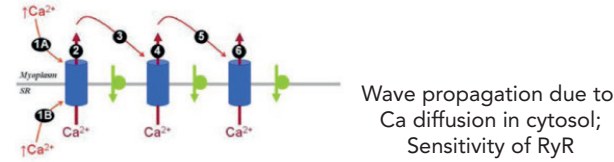

C

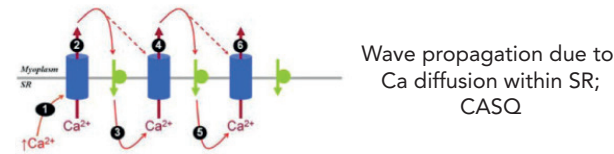

Panel A: Elements included are RyR Ca ${ }^{2+}$ release channel (blue), SERCA pump (green) both in the sarcoplasmic reticulum (SR) membrane that separates myoplasm and SR lumen (orange). Panel B: $\mathrm{Ca}^{2+}$ in myoplasm (step 1A) acts on first RyR cluster to open channel to release $\mathrm{Ca}^{2+}$ stored in $\mathrm{SR}$ to the myoplasm (step 2). This $\mathrm{Ca}^{2+}$ then diffuses away (step 3) and interacts with anatomically close RyR cluster (see Figures $2 \mathrm{~B}$ and $\mathrm{C}$ ) to cause further CICR (step 4). This process is regenerative and relies on sensitivity of RyR to $\mathrm{Ca}^{2+}$. Panel $\mathrm{C}: \mathrm{Ca}^{2+}$ wave propagation as in Panel $B$ but now wave propagation is also occurring in SR lumen. This process is thought to depend on calsequestrin (CASQ). Adapted from swietach et al. ${ }^{12}$

Figure 4: AP-evoked Global $\mathrm{Ca}^{2+}$ Transients in Purkinje Cells are Robust

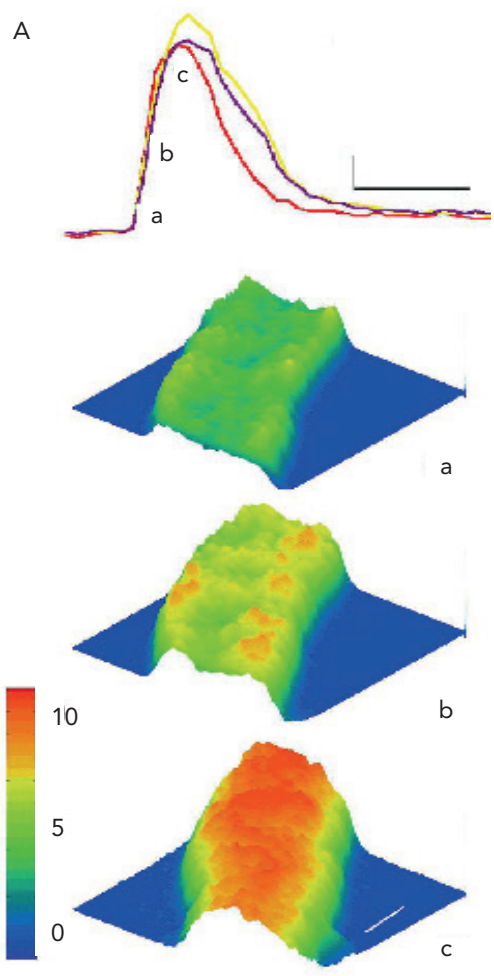

During the interval between stimuli, Purkinje cells are quiescent, except for occasional large $\mathrm{Ca}^{2+}$ waves (not shown here), which propagate along the cells of the aggregates. Panel A shows fluorescence intensity ( $\mathrm{Ca}^{2+}$ changes) in Purkinje cells during electrically evoked depolarisation. Note the fluorescence during an electrically-evoked $\mathrm{Ca}^{2+}$ transient in three ROIs is indicated. Small letters correspond to 3D surface plots (below) of ratio images of a section of this aggregate during the transient. $\mathrm{Ca}^{2+}$ concentration is reflected by both the colour and height of the surface. The first response to a stimulus is an increase in $\mathrm{Ca}^{2+}$ (panel a), which is present mostly at the aggregate's periphery (panel b). Peak $\mathrm{Ca}^{2+}$ change occurs later in core of aggregate (panel c). Thin calibration bars correspond to $1 \mathrm{~F} / \mathrm{FO}$ unit and $333 \mathrm{~ms}$, respectively, while white lines on surface plot (panel c) correspond to 10 m. From Boyden et al., 2003.

Figure 5A shows that spontaneous $\mathrm{Ca}^{2+}$ waves occur often during diastolic intervals in Purkinje cells dispersed from the infarcted heart? In some cases the waves formed varied oscillatory changes in voltage as
Figure 5: $\mathrm{Ca}^{2+}$ Waves Lead to Spontaneous Depolarisations
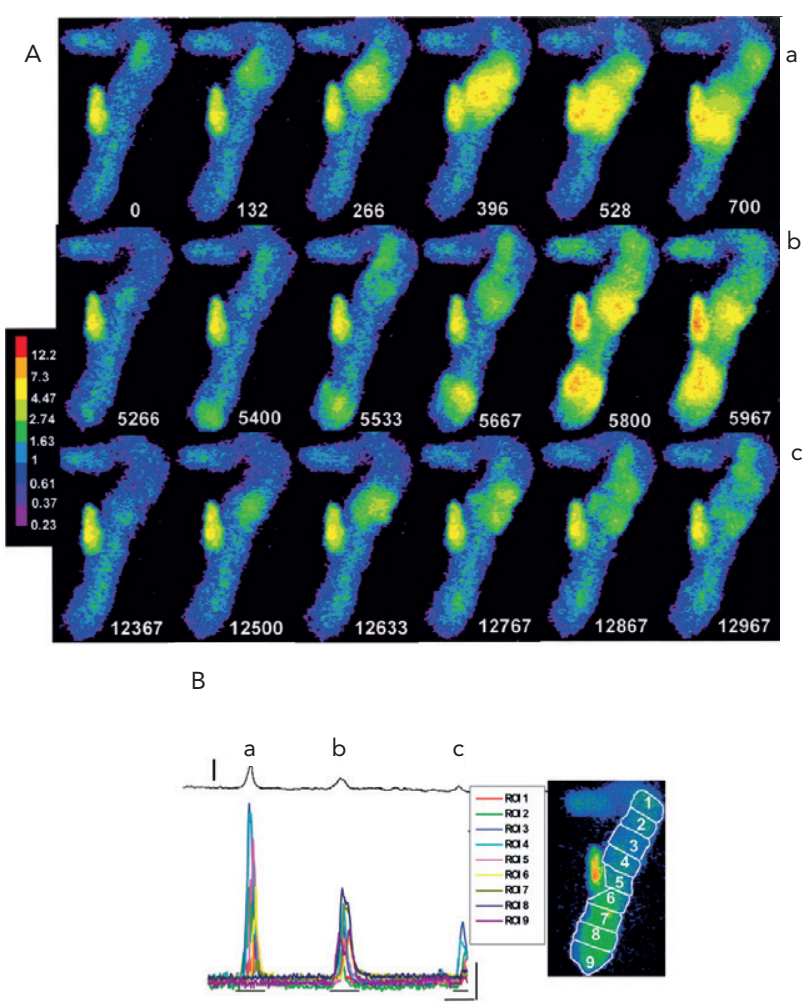

The magnitude of the depolarisation produced by the $\mathrm{Ca}^{2+}$ wave corresponds to the $\left[\mathrm{Ca}^{2+}\right]$ and extent of the $\mathrm{Ca}^{2+}$ transients. Panel A: Selected F/FO image frames from a Purkinje aggregate from the infarcted heart and concomitant membrane depolarisations (panel $B$ ). Relative time ( $t=0$ first frame) are white numbers. In panel Aa sequence, $t=0$ to $700 \mathrm{~ms}$ corresponds to F/FO during a large $\mathrm{Ca}^{2+}$ wave (see also a, panel B); In panel $\mathrm{Ab}$, $t=5266$ to 5967 ms corresponds to F/FO during two smaller waves which occur nearly simultaneously and propagate toward center of aggregate but stop before colliding (b, panel $B)$; in panel $A c, t=12,367$ to 12,967 ms corresponds to small micro $\mathrm{Ca}^{2+}$ transients which meander along upper section of aggregate ( $C$, panel $B$ ). Colour bar indicates ratio values. Panel $B$ : Transmembrane potential changes (thin black line above) and changes in F/FO of ROIs in the spontaneously active Purkinje cell of panel A. Amplitude as well as spatial extent of the waves (see panel A) varied considerably, giving rise to a corresponding membrane depolarisation (denoted by $a, b, c)$. Vertical line $15 \mathrm{mV}$. Image to right indicates positions of ROIs for this panel and panel $6 \mathrm{~B}$. Thin vertical and horizontal lines correspond to $1 \mathrm{~F} / \mathrm{FO}$ and 1,667 ms, respectively. Image frames of panel A derived from sections indicated by thin horizontal lines under $\mathrm{Ca}^{2+}$ tracings. From Boyden et al., 2003. ${ }^{7}$

$\mathrm{Ca}^{2+}$ of wave is pumped out of cell via the sodium-calcium exchanger $\left(I_{\mathrm{t} i}\right)$ (see Figure 5B). However, in the same cell the oscillatory voltage change is large enough to reach threshold, triggering a nondriven AP (see Figure 6). In these cells the small voltage signals and triggered activity are sensitive to an agent that blocks $\mathrm{Ca}^{2+}$ release of the RyR protein, ryanodine.

\section{Propagation Between Cardiac Cells}

Intercellular electrical transmission occurs via a set of ion channel proteins and specialised membrane structures called gap junctions. ${ }^{24}$ Each channel is formed by close apposition of two hemichannels each of which is in an opposing cell. ${ }^{25}$ Gap junctions can provide passage of many molecules (CAMP, $\mathrm{Ca}^{2+}, \mathrm{IP}_{3}$, ATP). ${ }^{26-28}$ In cardiac cells gap junctional conductance can be regulated acutely by $\mathrm{pH}, \mathrm{Ca}^{2+}$, CAMP and $\mathrm{CGMP}^{29}$ Therefore $\mathrm{Ca}^{2+}$ ions can flow through gap junctions as well as inhibiting gap junctional conductance.

Since $\mathrm{Ca}^{2+}$ waves propagate along the cell, it is important to know whether they propagate between cells via gap junctions. Many have observed $\mathrm{Ca}^{2+}$ waves passing between two cardiac cells ${ }^{30}$ and have assumed a role for gap junctions. $\mathrm{Ca}^{2+}$ ions released upon RyR activation can travel as a wave across cells ${ }^{31}$ and propagate to adjoining cells via gap junctions. ${ }^{19}$ In cells transfected with both 
Figure 6: Large Extensive $\mathrm{Ca}^{2}+$ Waves Lead to Sufficient Depolarisation to Elicit Nondriven APS
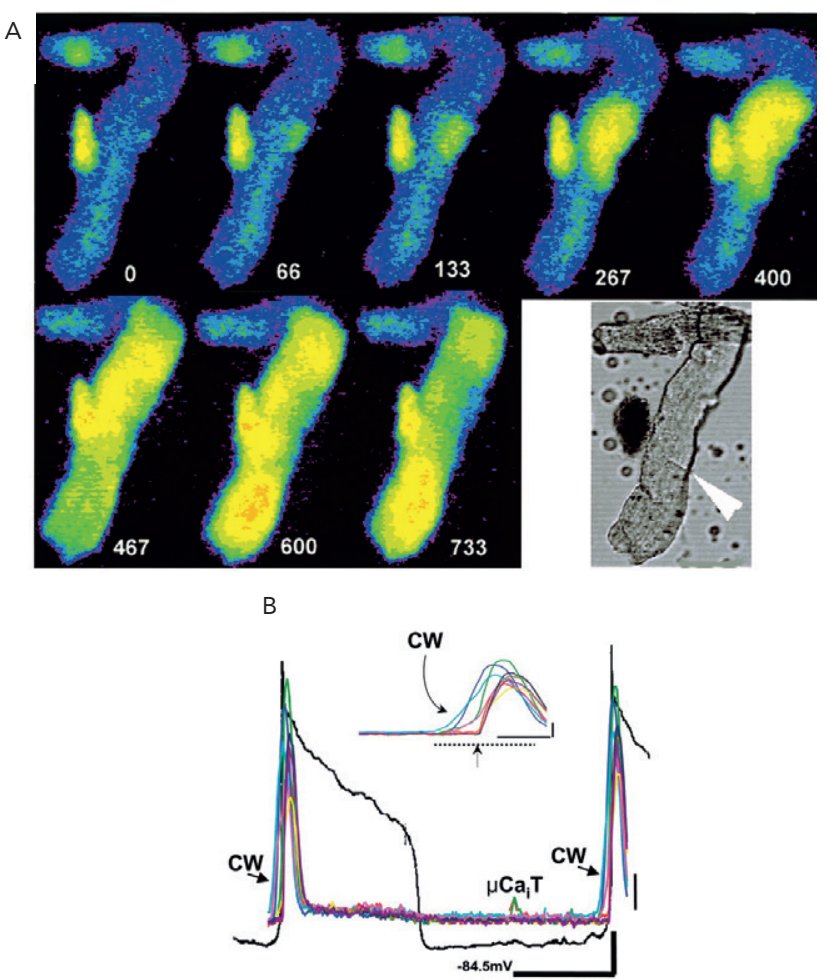

Panel A: Selected F/FO image frames from the same infarct Purkinje shown in Figure 5 but during $\mathrm{Ca}^{2+}$ wave induced electrical activity. Time relative to $t=0$ of first frame is depicted by white numbers. Lower right image is bright field image of this aggregate early during experiment. The arrow denotes a probable cell border. Colour code as in Figure 5A. Panel B: Transmembrane potential changes (black line) and changes in F/FO in several ROIs of spontaneously active Purkinje cell of panel A (MDP=-84.5 mV). Nondriven action potentials are triggered by the large cell wide $\mathrm{Ca}^{2+}$ waves $(\mathrm{CW})$. Inset shows enlargement of the $\mathrm{Ca}^{2}$ wave preceding synchronised $\mathrm{Ca}^{2+}$ release induced by the second action potential (arrow). Images presented in panel A are derived from those occurring during time of dotted line. Thick vertical and horizontal lines are one F/FO unit and $3 \mathrm{~s}$ ( 1 F/FO, $417 \mathrm{~ms}$ for inset), respectively. Thin vertical black line is $12 \mathrm{mV}$. From Boyden et al., $2003 .{ }^{7}$

connexin 43 (CX43) and RyR receptors the propagation of $\mathrm{Ca}^{2+}$ waves between cells was sensitive to octanol. ${ }^{32}$ Furthermore, in this experimental cell model, both $\mathrm{Ca}^{2+}$ wave propagation and gap junctional conductance between paired cardiac cells are related to the state of tyrosine phosphorylation of $\mathrm{C} \times 43 .{ }^{33} \mathrm{How}$ the $\mathrm{Ca}^{2+}$ wave crosses the gap junction is unknown but extracellular disulphide bonds of the $\mathrm{C} \times 43$ proteins between the adjoining cells appear critical for wave propagation. ${ }^{32}$

Arguably the occurrence of $\mathrm{Ca}^{2+}$ wave propagation from one cell to another is not a frequent event, but when one does happen, it appears to be due to a CICR mechanism (see Figure 7). In adult rat cells, $\mathrm{Li}$ et al. ${ }^{30}$ assert that $\mathrm{Ca}^{2+}$ wave propagation between cells mostly occurs at side-to-side junctions and the ultrastructure of the connections between the gap and SR release units is critical. Propagation failure occurs when distance between the disc membrane and neighbouring SR release unit is too large, such as occurs at end-to-end junctions.

At the tissue level, the subcellular $\mathrm{Ca}^{2+}$ dynamics combine with cell coupling and tissue architecture to generate multicellular $\mathrm{Ca}^{2+}$ wave dynamics. We understand focal electrical excitations due to triggered activity but are the dynamics of $\mathrm{Ca}$ waves similar? Spontaneous $\mathrm{Ca}^{2+}$ releases that triggered $\mathrm{Ca}^{2+}$ waves have been mapped in both normal and failing heart tissues ${ }^{34}$ (see Figure 8). ${ }^{35}$ Notably each
Figure 7: Intercellular $\mathrm{Ca}^{2+}$ Wave Propagation

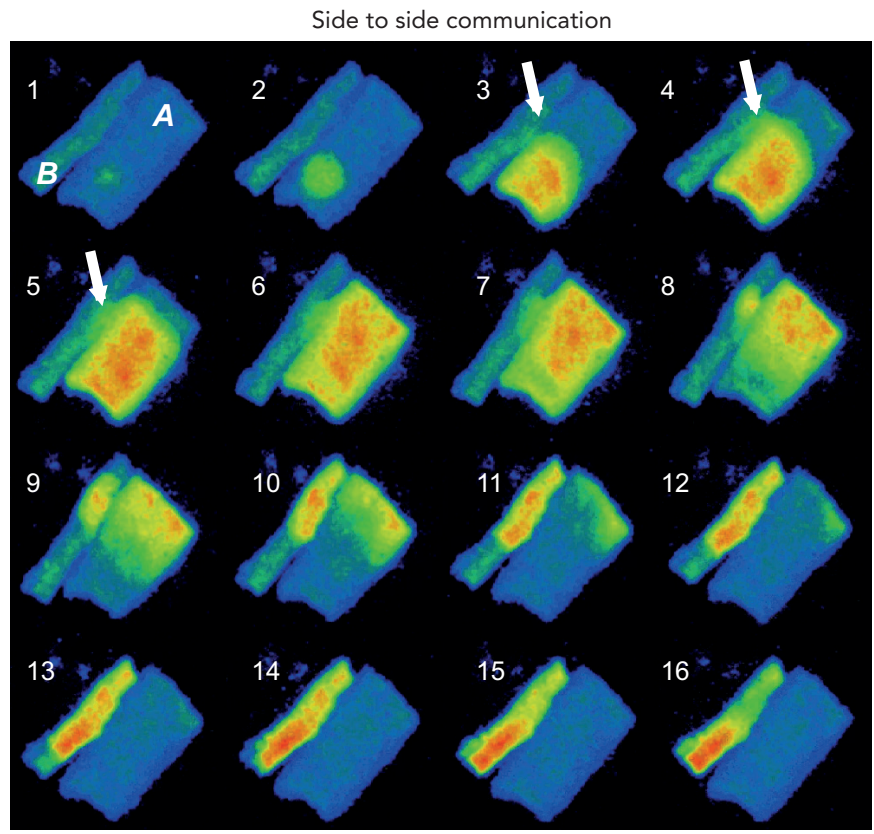

$\mathrm{Ca}^{2+}$ wave propagation in a pair of side-to-side canine Purkinje cells. Frames 1 and 2 show the initial $\mathrm{Ca}^{2+}$ release from the $\mathrm{SR}$ in cell $\mathrm{A}$. The $\mathrm{Ca}^{2+}$ release then propagates by $\mathrm{CICR}$ in cell A. Arrows in frames 3-5 indicate the passage of the wave from cell A to cell B. By frame 8 sufficient $\mathrm{Ca}^{2+}$ has changed in cell $B$ (yellow spot) to cause $\mathrm{Ca}^{2+}$ waves to propagate in both directions. The intracellular propagation velocity is $\sim 60 \mu \mathrm{m} / \mathrm{s}^{-1}$

Figure 8: Multicellular $\mathrm{Ca}^{2}+$ Wave Propagation

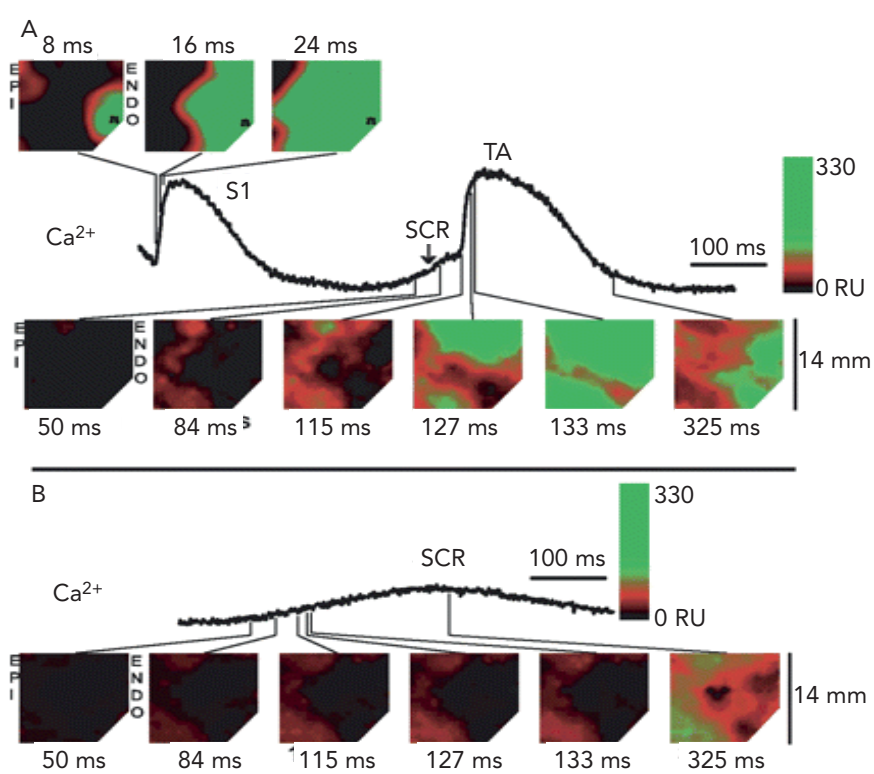

Shown are traces of two spontaneous $\mathrm{Ca}^{2+}$ release events (SCR) recorded from the same site in a single wedge preparation from a failing canine heart: one that resulted in a triggered beat (A) and one that did not (B). In A, above the last paced beat (S1) are three frames showing transmural $(14 \times 14 \mathrm{~mm})$ calcium level (amplitude) at select time points, demonstrating the rapid, uniform pattern of calcium release during pacing (pacing symbol). Below the trace are several frames of calcium levels from select time points during the SCR and subsequent triggered beat (TA). All times shown are relative to the earliest site of calcium release, during pacing (top) or the SCR (bottom). The Epi and Endo are shown on the left and right sides of each contour, respectively. For the colour scale, black corresponds to diastolic calcium, red corresponds to subthreshold SCR, and the transition from red to green corresponds to the threshold for TA in A. Calcium release is much slower during the SCR compared with pacing. In $B$, the exact same format is shown, except that frames of calcium levels during pacing are not shown. The colour scale created for $A$ was also used in B. In $A$ and B, SCRS occur in a relatively large aggregate of myocardial cells and achieved a similar amplitude; however, the rate of SCR rise is much greater in A when TA occurred compared with B when TA did not. From Hoeker et al., 2009. ${ }^{35}$ 
spontaneous event occurred in a region of myocardium comprised of many cells ( 3000 cells). ${ }^{34}$ In failing myocardium it is the rate of rise of the $\mathrm{Ca}^{2+}$ releases (waves) rather than their amplitude that is associated with triggered beats. In atria from CASQ-/- mice, the runs of APs during nondriven electrical activity were always preceded by rises in $\mathrm{Ca}^{2+}$, however total time of atrial activation increases with number of beats. ${ }^{36}$

\section{Refractoriness}

Electrical refractoriness is clearly related to time course of action potential repolarisation as well as the status of the sodium channel. In forward mode EC coupling, after the cellular action potential evoked $\mathrm{Ca}^{2+}$ transient due SR $\mathrm{Ca}^{2+}$ release, time is needed before a second $\mathrm{Ca}^{2+}$ release occurs of similar amplitude. Thus there is also a recovery process of $\mathrm{Ca}^{2+}$ release in cardiac cells that is independent of membrane voltage. In the electrically stimulated cell, the recovery of the $\mathrm{SR} \mathrm{Ca}^{2}+$ release process or refractoriness is determined by recovery of the L-type calcium channel influx as well as the time course of the SR refilling. The latter can be examined by assessing the interval between spontaneous $\mathrm{Ca}^{2+}$ sparks occurring at the same release site (see Figure 9). $\mathrm{Ca}^{2+}$ spark termination is due to local depletion of $\mathrm{Ca}^{2+}$ within junctional SR. The time between one spark and another is related to the ryanodine sensitivity or threshold for $\mathrm{Ca}^{2+}$ release. How fast junctional SR refills after depletion is important for the recovery of both spark amplitude and $\mathrm{CICR}$ or $\mathrm{Ca}^{2+}$ wave formation. ${ }^{37}$ Shortened refractoriness of this process has been seen in both acquired (post MI) ${ }^{38}$ and genetic disease. ${ }^{39}$ For example, loss of calsequestrin (CASQ) in SR of cells in some CVPT patients produces fast SR refilling and greater likelihood of a trigger for re-release ${ }^{40}$ and $\mathrm{Ca}^{2+}$ waves.

\section{Figure 9: Refractoriness of the $\mathrm{Ca}^{2}+$ Release Events}
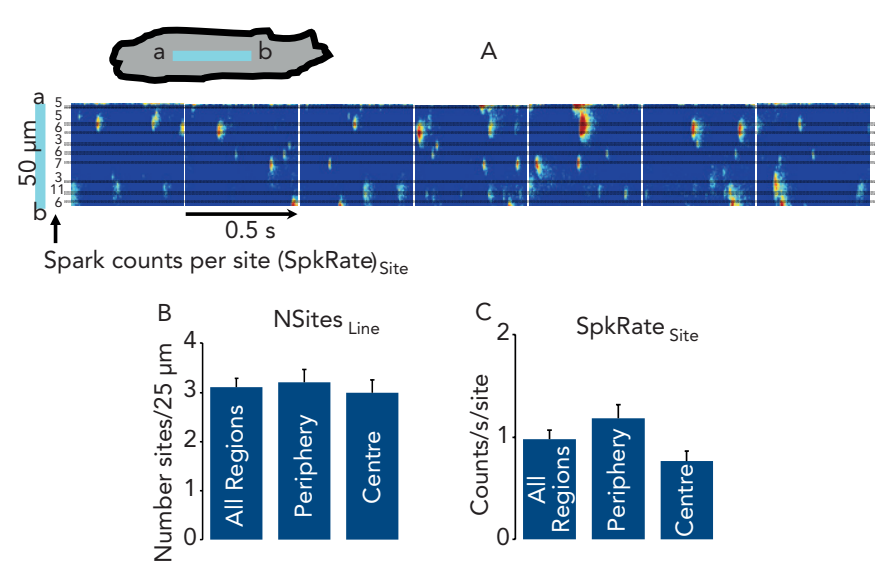

Panel A shows examples of line scan tracings (a-b) used to assess the refractoriness of $\mathrm{Ca}^{2+}$ releases in a normal Purkinje cell. Each fluorescent event represents a $\mathrm{Ca}^{2+}$ transient and corresponds to a $\mathrm{Ca}^{2+}$ release from a cluster of RyRs. Counting events along the scan indicates the regional density of active $\mathrm{Ca}^{2+}$ release sites (NSites ${ }_{L i n e,}$ Panel B) while horizontal event count reflects the frequency of $\mathrm{Ca}^{2+}$ release per site (SpkRate ${ }_{\text {Site, }}$ Panel $\mathrm{C}$ ).

\section{Conclusion}

While cellular electrical events and $\mathrm{Ca}^{2+}$ waves can occur independently of each other, it is when they interact and feed back on each other that complicated arrhythmogenic behaviour can occur (eg. alternans). ${ }^{4}$ Each physiological process has its own mechanisms of initiation, propagation and refractoriness and thus would be expected to have its own possible targets for effective therapeutic agents. For example, CamKII, ${ }^{41}$ sodiumcalcium exchanger protein ${ }^{42}$ and EHD3 ${ }^{43}$ proteins have all emerged as possible targets for $\mathrm{Ca}^{2+-}$-dependent arrhythmias.
Bozler E. The initiation of impulses in cardiac muscle. Amer J Physiol 1943; 138:273-82.

2. Lederer WJ, Tsien RW. Transient inward current underlying arrhythmogenic effects of cardiotonic steriods in Purkinje fibers. J Physiol 1976;263:73-100.

3. Kass RS, Lederer WJ, Tsien RW, Weingart R. Role of calcium ions in transient inward currents and aftercontractions induced by strophanthidin in cardiac Purkinje fibres. $J$ Physiol (Lond) 1978;281:187-208.

4. Ter Keurs HEDJ, Boyden PA. Calcium and arrhythmogenesis. Physiol Rev 2007;87:457-506.

5. Kleber AG, Rudy Y. Basic mechanisms of cardiac impulse propagation and associated arrhythmias. Physiol Rev 2004:84:431-88.

6. Dun W, Lowe JS, Wright PA, et al. Ankgrin-G participates in INa remodeling in myocytes from the broder zone of infarcted canine hearts. PloS ONE 2013; e78087.

7. Boyden PA, Barbhaiya C, Lee T, Ter Keurs HEDJ. Nonuniform $\mathrm{Ca}^{2+}$ transients in arrhythmogenic purkinje cells that survive in the infarcted canine heart. Cardiovasc Res 2003;57:681-93.

8. Thul R, Coombes S, Roderick HL, Bootman MD. Subcellular calcium dynamics in a whole-cell model of an atrial myocyte. Proc Natl Acad Sci 2012:109:2150-5.

9. Fabiato A. Time and calcium dependence of activation and inactivation of calcium induced release of calcium from the sarcoplasmic reticulum of a skinned cardiac Purkinje cell. J Gen Physiol 1985;85:247-90.

10. Fabiato A. Simulated calcium current can both cause loading in and trigger calcium release from the sarcoplasmic reticulum of a skinned canine cardiac Purkinje cell. I Gen Physiol 1985:85:291-320.

11. Fabiato A. Spontaneous versus triggered contractions of calcium tolerant cardiac cells from the adult rat ventricle. Basic Res Cardiol 1985:80(Suppl 2):83-8.

12. Swietach P, Spitzer KW, Vaughan-Jones RD. Modeling calcium waves in cardiac myocytes: importance of calcium diffusion. Front Biosci (Landmark Ed) 2010;15:661-80.

13. Jiang $D$, Xiao $B$, Yang $D$, et al. RyR2 mutations linked to ventricular tachycardia and sudden death reduce the threshold for store-overload-induced $\mathrm{Ca}^{2+}$ release (SOICR). Proc Natl Acad Sci 2004;101:13062-7.

14. Yano $\mathrm{M}$, Ikeda $\mathrm{Y}$, Matsuzaki $\mathrm{M}$. Altered intracellular $\mathrm{Ca}^{2+}$ handling in heart failure. I Clin Invest 2005;115:556-64

15. Wier WG, ter Keurs HE, Marban E, et al. $\mathrm{Ca}^{2+}$ 'sparks' and Wier WG, ter Keurs $\mathrm{HE}$, Marban $\mathrm{E}$, et al. $\mathrm{Ca}^{2+}$ 'sparks' and imaging. Circ Res 1997;81:462-9.
16. Shannon TR, Pogwizd SM, Bers DM. Elevated sarcoplasmic reticulum $\mathrm{Ca}^{2+}$ leak in intact ventricular myocytes from rabbits in heart failure. Circ Res 2003:93:592-4.

17. Miura M, Boyden PA, terkeurs HEDJ. $\mathrm{Ca}^{2}+$ waves during triggered propagated contractions in intact trabeculae: determinants of the velocity of propagation. Circ Res 1999;84:1459-68.

18. Lamont C, Luther PW, Wier WG. Intercellular $\mathrm{Ca}^{2}+$ waves in rat heart muscle. J Physiol 1998;512:669-76.

19. Stuyvers BD, Dun W, Matkovich SJ, et al. $\mathrm{Ca}^{2+}$ sparks and $\mathrm{Ca}^{2+}$ waves in Purkinje cells: a triple layered system of activation. Circ Res 2005;97:35-43.

20. di Barletta MR, Viatchenko-Karpinski S, Nori A, et al. Clinical phenotype and functional characterization of CASQ2 phenotype and functional characterization of CASQ2
mutations associated with catecholaminergic polymorphic mutations associated with catecholaminergic poly
ventricular tachycardia. Circ 2006;114;1012-9.

ventricular tachycardia. Circ 2006; 114;1012-9.
21. Wehrens XHT, Lehnart SE, Reiken S, et al. Enhancing calstabin binding to ryanodine receptors improves cardiac and skeletal muscle function in heart failure. PNAS 2005;102:9607-12.

22. Yano M, Ono K, Ohkusa $\mathrm{T}$, et al. Altered stoichiometry of FKBP12.6 versus ryanodine receptor as a cause of abnorma $\mathrm{Ca} 2+$ leak through ryanodine receptor in heart failure. Circ 2000:102:2131-6.

23. Bers DM, Eisner DA, Valdivia HH. Sarcoplasmic reticulum $\mathrm{Ca} 2+$ and heart failure: roles of diastolic leak and $\mathrm{Ca}^{2+}$ transport. Circ Res 2003;93:487-90.

24. Kleber AG, Rudy Y. Basic mechanisms of cardiac impulse propagation and associated arrhythmias. Physiol Rev 2004;84:431-88.

25. Yeager M. Structure of cardiac gap junction membrane channels. In: Spooner PM, Joyner RW, Jalife J, eds. Discontinuous Conduction in the Heart. First ed. Armonk: Futura; 1997;161-84.

26. Boitano S, Dirksen ER, Sanderson MJ. Intercellular propagation of calcium waves mediated by inositol triphosphate. Science 1992;258:292-5.

27. Saez JC, Connor JA, Spray DC, Bennett MV. Hepatocyte gap junctions are permeable to the second messenger, inositio 1,4,5-trisphosphate and to calcium ions. Proc Natl Acad Sci $1989 ; 86: 2708-12$

28. Sandberg K, Ji H, lida Y, Catt KJ. Intercellular communication between follicular angiotensin receptors and Xenopus laevis oocytes: mediation by an inositol 1,4,5-trisphosphatedependent mechanism. I cell Biol 1992;117:157-67.

29. Rosen MR, Boyden PA. Is there a pharmacology of discontinuous conduction? In: Spooner PM, Joyner RW,
Jalife J, eds. Discontinuous Conduction in the Heart. First ed. Armonk: Futura, 1997: 471-82.

30. Li Y, Eisner DA, O'Neill SC. Do calcium waves propagate between cells and synchronize alternating calcium release in rat ventricular myocytes? J Physiol 2012;590:6353-61

31. Zhang Y, Miura M, Ter Keurs HEDJ. Triggered propagated contractions in rat cardiac trabeculae; inhibition by octano and heptanol. Circ Res 1996;79:1077-85.

32. Toyofukyu T, Yabuki M, Otsu K, et al. Intercellular calcium signaling via gap junction in connexin43 transfected cells. J Biol Chem 1998;273:1519-28.

33. Toyofuku T, Yabuki M, Otsu K, et al. Functional role of c-Src in gap junctions of the cardiomyopathic heart. Circ Res 1999:85:672-81.

34. Katra RP, Laurita KR. Cellular mechanism of calcium-mediated triggered activity in the heart. Circ Res 2005;96:535-42.

35. Hoeker GS, Katra RP, Wilson LD, et al. Spontaneous calcium release in tissue from the failing canine heart. Am J Physiol Heart Circ Physiol 2009;297:H1235-42.

36. Lou Q, Belevych AE, Liu B, et al. Alternating membrane potential/calcium interplay underlies repetitive focal activity in a genetic model of calcium dependent atrial arrhythmias. J Physiol 2015;593:1443-58.

37. Ramay HR, Liu OZ, Sobie EA. Recovery of cardiac calcium release is controlled by sarcoplasmic reticulum refilling and ryanodine receptor sensitivity. Cardiovasc Res 2011;91:598-605.

38. Belevych AE, Terentyev D, Terentyeva R, et al. Shortened Ca2 signaling refractoriness underlies cellular arrhythmogenesis in a postinfarction model of sudden cardiac death. Circ Res 2012;110:569-77.

39. Brunello L, Slabaugh JL, Ho HT, et al. Decreased RyR2 refractoriness determines myocardial synchronization of aberrant $\mathrm{Ca} 2+$ release in a genetic model of arrhythmia. Proc Natl Acad Sci 2013:110:10312-7.

40. Liu N, Denegri M, Dun W, et al. Abnormal propagation of calcium waves and ultrastructural remodeling in recessive catecholaminergic polymorphic ventricular tachycardia. Circ Res 2013;113:142-52.

41. Pellicena P, Schulman H. CaMKII inhibitors: from research tools to therapeutic agents. Front Pharmacol 2014;5:21.

42. Nagy N, Kormos A, Kohajda Z, et al. Selective $\mathrm{Na}+/ \mathrm{Ca} 2+$ exchanger inhibition prevents $\mathrm{Ca} 2+$ overload-induced triggered arrhythmias. Br I Pharmacol 2014:171:5665-81.

43. Curran J, Makara MA, Little SC, et al. EHD3-dependent endosome pathway regulates cardiac membrane excitability and physiology. Circ Res 2014;115:68-78. 